\title{
Transmurality mapping of left ventricular scar: impact of spatial resoluton
}

\author{
Dana C Peters ${ }^{1 *}$, Felix Liu', Alex Tan¹, Benjamin R Knowles ${ }^{1}$, Heather S Duffy' ${ }^{1}$ Andrew L Wit ${ }^{2}$, Mark E Josephson', \\ Warren J Manning ${ }^{1}$
}

From 2011 SCMR/Euro CMR Joint Scientific Sessions

Nice, France. 3-6 February 2011

\section{Purpose}

To generate scar transmurality maps, to study the impact of spatial resolution on these maps.

\section{Introduction}

Left ventricular (LV) scar is associated with ventricular tachycardia (VT), related to regions of slow conduction. Endocardial LV voltage maps reveal regions of low voltage near the site of VT origin, corresponding to myocardial fiber bundles trapped in areas of extensive fibrosis. Scar transmurality (i.e. the percent of myocardial wall thickness which is scarred, measured in 6-12 sectors around the LV myocardium) is an indicator of myocardial viability after reperfusion (1). Intermediate infarct transmurality has been correlated with nonischemic VT (2). Furthermore, lower voltages are found in regions of more transmural scarring (3). We have expanded the transmurality concept to generate LGE transmurality maps of the LV.

\section{Methods}

3D LGE studies (4) from 8 patients with prior myocardial infarction were obtained on a $1.5 \mathrm{~T}$ Achieva CMR system (Philips Healthcare, Best, NL). Imaging parameters were: $0.2 \mathrm{mmol} / \mathrm{kg}$ Gd-DPTA, inversion recovery gradient echo sequence with fat-saturation, with ECG and NAV-gating: TR/TE $/ \theta=5.6 \mathrm{~ms} / 2.6 \mathrm{~ms} / 25^{\circ}, 4-6 \mathrm{~min}-$ utes/scan. Figure 1 illustrates the processing to generate 3D endocardial transmurality maps, using original high $\left(1.3 \times 1.3 \times 4 \mathrm{~mm}^{3}\right)$ and processed lower $\left(2 \times 2 \times 8 \mathrm{~mm}^{3}\right)$ resolution images. All processing was performed in Matlab (v7.1, Mathworks, Natick, MA), with visualization using Paraview (v3.8 Kitware, Clifton Park, NY).

${ }^{1}$ Beth Israel Deaconess Medical Center, Boston, MA, USA

Full list of author information is available at the end of the article
Bipolar voltage maps, obtained by electrophysiological (EP) catheter mapping, were compared with transmurality maps visually. High and low resolution transmurality maps were compared visually. Average transmurality of scarred sectors was compared, using a paired t-test.

\section{Results}

In 4 subjects with voltage maps, regions with greater transmurality had lower voltage electrograms (Fig 1E,F). Low resolution data produced greater transmurality by visual assessment in $88 \%$ of subjects (Figure 2). Quantitatively, the average scar transmurality in scarred sectors for high and low resolution transmurality maps were 30 $\pm 4 \%$ and $37 \pm 5 \%, \mathrm{p}=0.001$, respectively.

\section{Conclusions}

We present a novel method for displaying transmurality of enhancement from 3D LGE images. The relationship between transmurality maps and voltage must be further in explored in a larger cohort, using quantitative means. Maps derived from higher resolution images demonstrated less transmural scar. Since scar that encompasses

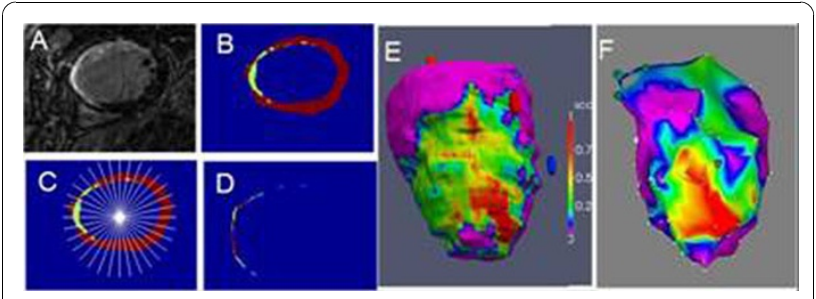

Figure 1 A) Starting with a short axis LGE image (A), scar and myocardium are segmented (B). Scar transmurality is calculated in 100 sectors in each slice (C), which provides an endocardial representation of LV scar (D). E) Scar transmurality map (1=100\%) transmural) is displayed in 3D. F) The corresponding bipolar voltage maps shows strong similarity (scale $=0.5 / 0.05 \mathrm{mV}$ ). 


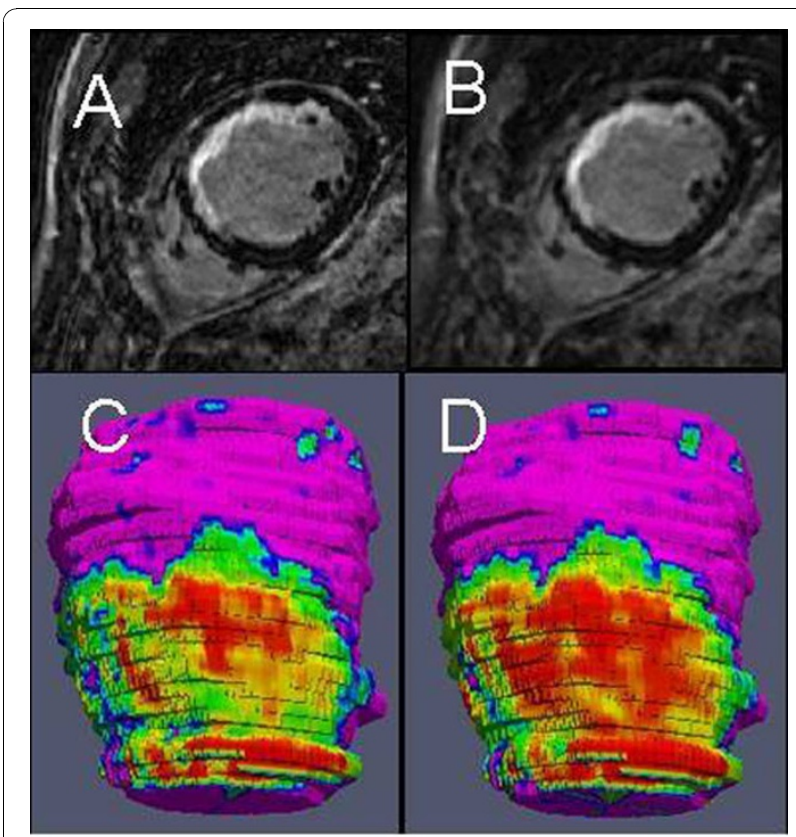

Figure 2 Example higher (A) and lower (B) resolution LGE images, and respective transmurality maps from higher (C) and lower (D) resolution images.

surviving myocardium (i.e. almost transmural scar) may be related to VT genesis, high resolution transmurality mapping might be useful in detecting the true arrhythmogenic substrate.

\section{Author details}

${ }^{1}$ Beth Israel Deaconess Medical Center, Boston, MA, USA. ${ }^{2}$ Columbia University, New York, NY, USA.

Published: 2 February 2011

\section{References}

1. Kim RJ: NEJM 2001.

2. Nazarian S: Circ 2005

3. Wolf T, et al: JACC 2001.

4. Peters DC, et al: JMRI 2009

doi:10.1186/1532-429X-13-S1-P163

Cite this article as: Peters et al.: Transmurality mapping of left

ventricular scar: impact of spatial resoluton. Journal of Cardiovascular

Magnetic Resonance 2011 13(Suppl 1):P163.

\section{Submit your next manuscript to BioMed Central} and take full advantage of:

- Convenient online submission

- Thorough peer review

- No space constraints or color figure charges

- Immediate publication on acceptance

- Inclusion in PubMed, CAS, Scopus and Google Scholar

- Research which is freely available for redistribution

Submit your manuscript at www.biomedcentral.com/submit
Biomed Central 